\title{
Adolescents notice fewer tobacco displays after implementation of the point-of-sale tobacco display ban in Finland
}

\author{
Jaana M. Kinnunen' ${ }^{1}$, Hanna Ollila ${ }^{2}$, Anu Linnansaari', David S. Timberlake ${ }^{1,3}$, Mirte A.G. Kuipers ${ }^{4}$, Arja H. Rimpelä',5,6
}

\begin{abstract}
INTRODUCTION Finland implemented a point-of-sale (POS) display ban for tobacco products and their trademarks in 2012, and for electronic cigarettes in 2016. In this study we examine whether noticing tobacco products changed among adolescents after the implementation of the display ban and describe the noticing of e-cigarette displays post-implementation.

METHODS Repeated cross-sectional national survey data of 12- to 16-year-olds from years 2011, 2013, 2015 and 2017 were used. Measures included adolescent self-report on noticing displays of tobacco and e-cigarettes in shops, kiosks and service stations. Adjusting for age, gender, smoking and academic achievement, logistic regression analyses were conducted by retailer type to test the association between survey year and noticing POS tobacco displays.

RESULTS The proportions of adolescents noticing tobacco displayed in shops, kiosks and service stations decreased from 2011 to 2013 (from over $80 \%$ to about $30 \%$ ). Between 2013 and 2017, exposure to tobacco displays decreased for kiosks but slightly increased for shops and service stations. However, in all retailer types, rates in 2017 were still well below the pre-ban levels of 2011. In 2017, noticing e-cigarette displays by 12 - to 16 -year-old adolescents was reported by $5.6 \%$ in shops, $20.5 \%$ in kiosks and $5.1 \%$ in service stations.

concLusions The pronounced decline in adolescents' exposure to tobacco products at POS observed in the current study implies adherence to the ban, as intended by the law. We encourage more countries to enact POS tobacco advertising and display bans, and to enforce the POS regulations to all tobacco products and novel nicotine delivery systems.
\end{abstract}

\begin{abstract}
AFFILIATION
1 Faculty of Social Sciences, Health Sciences, Tampere University, Tampere, Finland 2 Alcohol, Drugs and Addictions Unit, Department of Public Health Solutions, National Institute for Health and Welfare, Helsinki, Finland

3 Program in Public Health, College of Health Sciences, University of California, Irvine, United States 4 Department of Public Health, Amsterdam Public Health Research Institute, Amsterdam UMC, University of Amsterdam, Amsterdam, the Netherlands 5 PERLA - Tampere Centre for Childhood, Youth and Family Research, Tampere University, Tampere, Finland

6 Department of Adolescent Psychiatry, Pitkäniemi Hospital, Tampere University Hospital, Nokia, Finland
\end{abstract}

\section{CORRESPONDENCE TO}

Jaana M. Kinnunen. Faculty of Social Sciences, Health Sciences, P.O. Box 100, FI-33014 Tampere University, Tampere, Finland. E-mail: jaana.kinnunen@tuni.fi ORCID ID: https://orcid.org/00000002-2772-7969

\section{KEYWORDS}

point-of-sale display ban, tobacco, electronic cigarettes, adolescents, Finland

Received: 5 November 2018 Revised: 17 January 2019

Accepted: 15 February 2019

\section{INTRODUCTION}

Tobacco product display has become one of the tobacco industry's most important forms of tobacco promotion as restrictions have increasingly been placed on tobacco advertising ${ }^{1}$. A large body of evidence ${ }^{2-8}$ shows that exposure to point-of-sale (POS) tobacco promotion is positively associated with smoking and smoking susceptibility among adolescents. Article 13 of the WHO Framework Convention on Tobacco Control (FCTC) obligates the Parties to the treaty to 
prohibit 'any form of commercial communication, recommendation or action with the aim, effect or likely effect of promoting a tobacco product or tobacco use either directly or indirectly ${ }^{9}$. The guidelines for the implementation of Article 13 directly state that 'Display and visibility of tobacco products at points of sale constitutes advertising and promotion and should therefore be banned ${ }^{10}$.'

Previous studies have shown that a tobacco POS display ban can decrease adolescents' observation of tobacco products in stores. In Ireland, adolescents' recall of tobacco product displays decreased from $81 \%$ before the display ban to $22 \%$ after its implementation in $2009^{11}$. A less dramatic decline (from $80 \%$ to $64 \%$ ) occurred among adolescents and young adults following a display ban in Australia in New South Wales in 2010 and in Queensland in $2011^{2}$. In 2012, tobacco POS displays were banned in large shops in England; the proportion of children noticing tobacco products in supermarkets decreased from $60 \%$ to $46 \%{ }^{12}$.

Even though previous studies have shown a decrease in noticing tobacco products displayed after the ban, the follow-up times have been limited, and differences by types of shops have not been studied. Retailers may expect to see a reduction in sales as a consequence of the ban, which may reduce retailers' adherence to the ban. Since adherence and enforcement may decline over time, it is important to monitor exposure to POS displays over a long period.

In Finland, the display of tobacco products and their trademarks at the POS were banned in a provision to the Tobacco Act in 2010, and subsequently implemented at the beginning of $2012^{13}$. In practice, this means that all tobacco products have to be kept in closed containers, cabinets or drawers, or behind sliding doors or similar kinds of arrangement. This ban also applies to smoking accessories if they have a tobacco product trademark. Upon request of a customer, the retailer can show a printed catalogue or a list of tobacco products and their sale prices, given that the list does not have any promotional elements.

While most countries with tobacco display bans still allow the display of electronic cigarettes (e-cigarettes), Finland extended the display ban to e-cigarettes through a revision of the Tobacco Act in August 2016 ${ }^{14}$. Until 2016, nicotine containing e-cigarettes were regulated under the Medicines Act, and thus regular retailers were not allowed to sell these products. However, between 2012 and 2016, regular retailers were able to display nonnicotine e-cigarettes. Previous studies have shown an association between adolescents' observation of e-cigarette displays and susceptibility to and use of e-cigarettes among adolescents ${ }^{15,16}$. It is therefore important to monitor the exposure to in-store displays of e-cigarettes.

The aim of this study was to investigate the changes in Finnish adolescents' observation of tobacco products on display in shops, kiosks and service stations from 2011 (before the display ban) until 2017 (after the display ban) using data from 2011, 2013, 2015 and 2017. To our knowledge, this is the first study that has examined adolescents' exposure to the POS display of e-cigarettes and which has monitored the long-term trend of adolescents' exposure to displayed tobacco products at point of sales.

\section{METHODS}

\section{Sampling and participants}

Data were analysed from the 2011, 2013, 2015 and 2017 nationwide Adolescent Health and Lifestyle Surveys. Nationally representative samples were obtained from the Population Register Centre. All Finns aged 12, 14 and 16 years, born on certain dates in June, July or August, were selected. Approvals from the Ethics Committee of the Tampere region were obtained for study protocols. No parental consent was needed, and filling in the questionnaire was considered as the adolescents' consent to participate.

The same protocol was followed every survey year and questionnaires were mailed to adolescents in February of each survey year, followed by three reminders to the non-respondents. The overall response rate was $45 \%$, ranging from $40 \%$ in 2013 to $50 \%$ in 2011 (Table 1). The overall response rate for boys was $38 \%$ and for girls $52 \%$, while for 12 -year-olds it was $47 \%$, for 14 -year-olds $38 \%$ and for 16 -year-olds $42 \%$. The proportion of missing answers was less than $3 \%$.

\section{Measures}

Noticing tobacco product displays was measured separately for shops (i.e. smaller local grocery stores 
Table 1. Descriptive characteristics of the study populations and the frequencies of the responses to questions on noticing tobacco products displayed in shops, kiosks and service stations

\begin{tabular}{|c|c|c|c|c|c|}
\hline Characteristics & 2011 & 2013 & 2015 & 2017 & All years \\
\hline Sample, $n$ & 6987 & 6539 & 11749 & 6725 & 32000 \\
\hline Respondents, n & 3478 & 2619 & 5140 & 3083 & 14320 \\
\hline Response rate, $\%$ & 50 & 40 & 44 & 46 & 45 \\
\hline \multicolumn{6}{|c|}{$\begin{array}{l}\text { Noticed tobacco products displayed } \\
\text { in shops }\end{array}$} \\
\hline Yes, n (\%) & 2914 (83.8) & $954(36.4)$ & $1954(38.0)$ & $1483(48.1)$ & $7305(51.0)$ \\
\hline No, n (\%) & $450(12.9)$ & 1535 (58.6) & $2936(57.1)$ & $1453(47.1)$ & $6374(44.5)$ \\
\hline Do not usually visit, n (\%) & $87(2.5)$ & $79(3.0)$ & $194(3.8)$ & $125(4.1)$ & $485(3.4)$ \\
\hline Missing information, n (\%) & $27(0.8)$ & $51(2.0)$ & $56(1.1)$ & $22(0.7)$ & $156(1.1)$ \\
\hline $\mathrm{N}$ in analyses ${ }^{\mathrm{a}}$ & 3364 & 2489 & 4890 & 2936 & 13679 \\
\hline \multicolumn{6}{|c|}{$\begin{array}{l}\text { Noticed tobacco products displayed } \\
\text { in kiosks }\end{array}$} \\
\hline Yes, n (\%) & $2033(58.5)$ & $645(24.6)$ & $1194(23.2)$ & 425 (13.8) & $4297(30.0)$ \\
\hline No, n (\%) & 480 (13.8) & $1197(45.7)$ & $2383(46.4)$ & 2458 (79.7) & $6518(45.5)$ \\
\hline Do not usually visit, n (\%) & $896(25.8)$ & 705 (26.9) & $1467(28.5)$ & $152(4.9)$ & $3220(22.5)$ \\
\hline Missing information, n (\%) & $69(2.0)$ & $72(2.7)$ & $96(1.9)$ & $48(1.6)$ & $285(2.0)$ \\
\hline $\mathrm{N}$ in analyses ${ }^{\mathrm{a}}$ & 2513 & 1842 & 3577 & 2883 & 10815 \\
\hline \multicolumn{6}{|c|}{$\begin{array}{l}\text { Noticed tobacco products displayed } \\
\text { in service stations }\end{array}$} \\
\hline Yes, n (\%) & $1690(48.6)$ & $488(18.6)$ & 865 (16.8) & $750(24.3)$ & $3793(26.5)$ \\
\hline No, n (\%) & 411 (11.8) & $1056(40.3)$ & $2081(40.5)$ & $1238(40.2)$ & $4786(33.4)$ \\
\hline Do not usually visit, n (\%) & $1298(37.3)$ & 989 (37.8) & $2077(40.4)$ & $1057(34.3)$ & $5421(37.9)$ \\
\hline Missing information, n (\%) & $79(2.3)$ & $86(3.3)$ & $117(2.3)$ & $38(1.2)$ & $320(2.2)$ \\
\hline $\mathrm{N}$ in analyses ${ }^{\mathrm{a}}$ & 2101 & 1544 & 2946 & 1988 & 8579 \\
\hline
\end{tabular}

a Only those adolescents who visited the places were included in the analyses

and large supermarkets), kiosks and service stations with the question: 'During the last 30 days, have you noticed tobacco products displayed in following places near your home, school or workplace?; with options 'Yes', 'No' and 'I do not usually visit this place'. In 2017, noticing of tobacco and of e-cigarettes were measured separately, as noticing e-cigarette displays was studied for the first time. Only responses of those who visited the places under study were included in the analyses, as the focus of this study was to measure the changes in exposure as a result of the POS display ban, not changes in visits. Table 1 also shows the number of respondents in the analyses.

Selected sociodemographic characteristics were used as controlling variables. Respondents' age and gender were received from the Population Register Centre. Academic achievement was based on subjective assessment of their performance in school compared with the class average: 'much or slightly better', 'about class average', and 'slightly or much poorer'. Smoking status was categorised into three groups: never-smokers, experimenters (as having tried smoking but not smoking daily) and daily smokers.

\section{Data analysis}

Noticing tobacco products was cross-tabulated with survey year by retailer type, age and gender. Prevalence of noticing e-cigarettes on display was separately calculated for each retailer type in 2017. Logistic regression analyses were then conducted by retailer type to test the association between survey year and exposure to tobacco displays. In these analyses, age, gender, smoking status and academic achievement were controlled for, as they may have influenced noticing tobacco products. For the adjusted prevalence of noticing tobacco products, direct adjustment was used with an equal weight applied to each group. A trend test was conducted with the Linear-by-Linear Association (LLA). IBM SPSS Statistics V.23 was used for data analyses. 


\section{RESULTS}

Table 2 describes the proportions of noticing tobacco products on display in shops, kiosks and service stations by age and gender groups. In most of the groups, girls reported more observation of tobacco products compared to boys, and the 14-year-olds reported more observation of tobacco products compared to 12- and 16-year-olds. However, the proportion differences between groups were not systematic (Table 2).

Figure 1 shows the proportions of 12- to 16-yearold adolescents reporting tobacco products on display in shops, kiosks, and service stations in Finland in 2011-2017. In 2011, over $80 \%$ of 12 to 16-year-olds had noticed tobacco products on display in shops, kiosks and service stations; in contrast, approximately one-third of adolescents had observed a tobacco product on display in 2013. From 2013 to 2015 , the proportions remained quite stable. From 2015 to 2017, they further decreased for kiosks but slightly increased for shops and service stations (Figure 1). Figures 2 and 3 show the corresponding proportions for boys and girls, which are very similar to the proportions in Figure 1.

Compared to 2011, the odds ratios for noticing tobacco POS displays in 2013 ranged from 0.09 (95\% CI: 0.08-0.11) for shops to 0.13 (95\% CI: 0.110.15 ) for kiosks (Table 3). Table 3 also shows the adjusted proportions for noticing tobacco products on display in shops, kiosks, and service stations,

Table 2. Percentage of 12- to 16-year-old adolescents who had noticed tobacco products on display in shops, kiosks, and service stations, in 2011-2017 in Finland, among adolescents who visited the places by age (years) and gender

\begin{tabular}{|c|c|c|c|c|c|c|c|c|c|c|c|c|}
\hline & \multicolumn{4}{|c|}{ Shops } & \multicolumn{4}{|c|}{ Kiosks } & \multicolumn{4}{|c|}{ Service stations } \\
\hline & 2011 & 2013 & 2015 & 2017 & 2011 & 2013 & 2015 & 2017 & 2011 & 2013 & 2015 & 2017 \\
\hline \multicolumn{13}{|l|}{ Boys } \\
\hline 12 & 81.6 & 37.7 & 40.1 & 46.0 & 68.9 & 24.3 & 27.1 & 10.3 & 68.1 & 23.6 & 25.1 & 28.5 \\
\hline 14 & 87.1 & 43.8 & 41.0 & 52.8 & 78.7 & 35.3 & 34.1 & 18.1 & 80.3 & 34.8 & 30.8 & 39.2 \\
\hline 16 & 83.8 & 32.7 & 37.8 & 44.8 & 79.4 & 31.6 & 36.3 & 18.0 & 80.0 & 29.1 & 30.1 & 37.9 \\
\hline \multicolumn{13}{|l|}{ Girls } \\
\hline 12 & 86.8 & 43.7 & 40.8 & 52.8 & 75.5 & 38.5 & 27.3 & 5.2 & 76.5 & 32.3 & 22.9 & 25.1 \\
\hline 14 & 89.0 & 40.7 & 43.1 & 55.0 & 82.8 & 38.0 & 37.4 & 14.5 & 78.9 & 36.1 & 33.4 & 42.3 \\
\hline 16 & 87.7 & 34.0 & 36.7 & 48.5 & 87.4 & 37.6 & 34.3 & 16.6 & 86.9 & 30.4 & 29.9 & 43.0 \\
\hline Total & 86.6 & 38.3 & 40.0 & 46.7 & 80.9 & 35.0 & 33.4 & 14.7 & 80.4 & 31.6 & 29.4 & 37.7 \\
\hline
\end{tabular}

Table 3. Prevalence (\%) and odds ratios (95\% confidence interval) of 12- to 16 -year-old adolescents, who visited the following places, for noticing tobacco products on display in shops, kiosks, and in service stations, in 2011-2017, controlled for age, gender, smoking status and academic achievement, and prevalence (\%) of 12- to 16-year-old adolescents, who visited the places, for noticing e-cigarettes on display in shops, kiosks, and in service stations in 2017 in Finland

\begin{tabular}{|c|c|c|c|c|c|c|}
\hline \multirow[t]{2}{*}{ Year } & \multicolumn{2}{|c|}{ Shops } & \multicolumn{2}{|c|}{ Kiosks } & \multicolumn{2}{|c|}{ Service stations } \\
\hline & $\%$ & OR $\left(95^{\circ} \%(C I)^{\mathrm{a}}\right.$ & $\%$ & OR $\left(95^{\circ} \% \mathrm{CI}\right)^{\mathrm{a}}$ & $\%$ & OR $\left(95^{\circ} \%(C I)^{a}\right.$ \\
\hline \multicolumn{7}{|l|}{ Tobacco } \\
\hline 2011 & 86.9 & 1.00 & 81.7 & 1.00 & 81.1 & 1.00 \\
\hline 2013 & 37.6 & $0.09(0.08-0.11)$ & 34.6 & $0.13(0.11-0.15)$ & 31.0 & $0.11(0.10-0.13)$ \\
\hline 2015 & 40.6 & $0.10(0.09-0.12)$ & 34.7 & $0.13(0.11-0.14)$ & 30.7 & $0.11(0.09-0.12)$ \\
\hline 2017 & 50.5 & $0.16(0.14-0.18)$ & 16.1 & $0.04(0.04-0.05)$ & 37.4 & $0.16(0.14-0.18)$ \\
\hline$p^{b}(2011-2017)$ & $<0.001$ & & $<0.001$ & & $<0.001$ & \\
\hline$p^{b}(2013-2017)$ & $<0.001$ & & $<0.001$ & & $<0.001$ & \\
\hline \multicolumn{7}{|l|}{ E-cigarettes } \\
\hline 2017 & 5.6 & & 20.5 & & 5.1 & \\
\hline
\end{tabular}

a Binary logistic regression, adjusted for age, gender, academic achievement and smoking status. b Linear-by-Linear Association. 
Figure 1. Percentages of 12-to 16-year-old adolescents, who visited the following places, reporting noticing tobacco products on display in shops, kiosks, and service stations in 2011-2017 in Finland

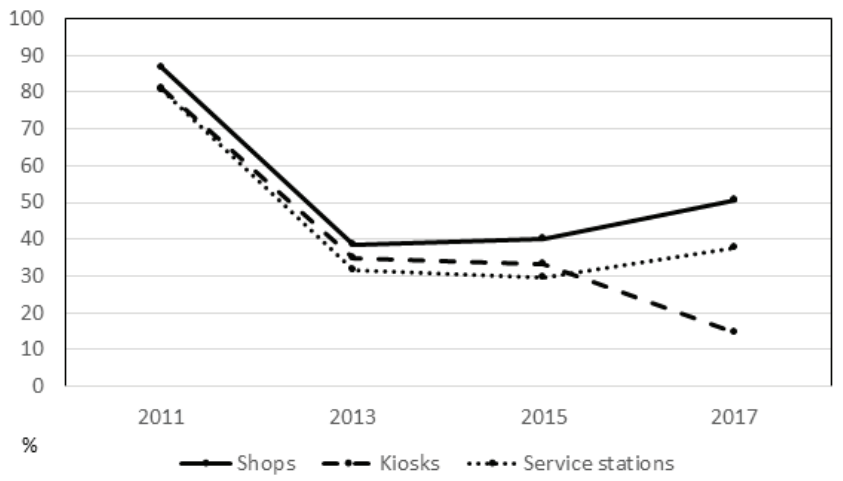

Figure 2. Percentages of 12 - to 16-year-old boys, who visited the following places, reporting noticing tobacco products on display in shops, kiosks, and service stations in 2011-2017 in Finland

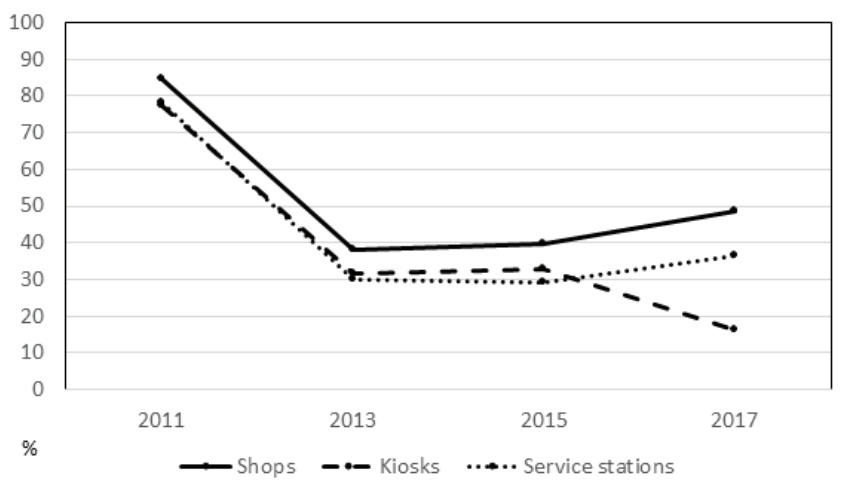

Figure 3. Percentages of 12 - to 16 -year-old girls, who visited the following places, reporting noticing tobacco products on display in shops, kiosks, and service stations in 2011-2017 in Finland

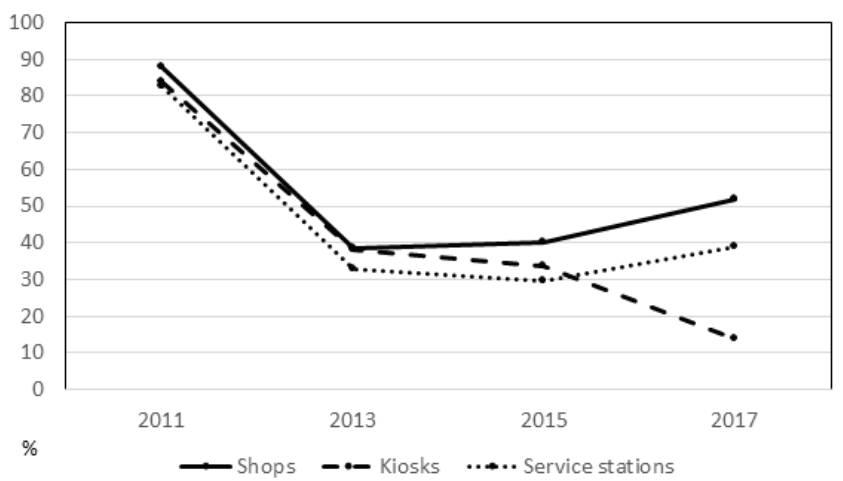

which slightly differ from the unadjusted estimates in Figure 1. Trends over years 2011-2017 and 20132017 were statistically significant in all retailer types $(\mathrm{p}<0.001)($ Table 3).

In $2017,5.6 \%$ of 12 - to 16 -year-old adolescents had noticed e-cigarettes displayed in shops, $20.5 \%$ in kiosks and $5.1 \%$ in service stations (Table 3 ).

\section{DISCUSSION}

Our study reports a substantial decline in Finnish adolescents' observation of tobacco products on display in shops, kiosks and service stations after implementation of the display ban. The decrease continued for kiosks for the measured six years, while a slight increase was observed for shops and service stations between 2015 and 2017. The proportions of adolescents' observation of tobacco products were, though, much lower compared to the period preceding the ban. The proportions of those who had noticed e-cigarettes displayed in shops and service stations were smaller compared to tobacco.

In Ireland ${ }^{11}$, Scotland ${ }^{17}$ and Australia ${ }^{2}$, approximately $80 \%$ of adolescents reported noticing tobacco displays before the ban, in agreement with our pre-ban estimates. The decline in noticing tobacco displays was similar to ours in Ireland $(81 \% \text { to } 22 \%)^{11}$, but less dramatic in England ${ }^{12}$ and Australia ${ }^{2}$. These proportions are shown in Table 4.

Table 4. The proportions (\%) of noticing tobacco displays in Finland, Ireland, England, Scotland and Australia before and after the display ban

\begin{tabular}{|c|c|c|c|c|}
\hline Country & $\begin{array}{l}\text { Before } \\
\text { the } \\
\text { ban } \\
(\%)\end{array}$ & $\begin{array}{l}\text { Afier } \\
\text { the } \\
\text { ban } \\
(\%)\end{array}$ & $\begin{array}{l}\text { Age } \\
\text { group } \\
\text { (years) }\end{array}$ & $\begin{array}{l}\text { Research } \\
\text { method }\end{array}$ \\
\hline Finland & & & $12-16$ & $\begin{array}{c}\text { Biennial postal } \\
\text { survey }\end{array}$ \\
\hline Shops & 87 & 38 & & \\
\hline Kiosks & 81 & 35 & & \\
\hline Service stations & 80 & 32 & & \\
\hline Ireland ${ }^{11}$ & & & $13-15$ & $\begin{array}{l}\text { Face-to-face in- } \\
\text { home interview }\end{array}$ \\
\hline Shops & 81 & 22 & & \\
\hline England $^{12}$ & & & $11-16$ & Cohort study \\
\hline Supermarkets & 60 & 46 & & \\
\hline Scotland ${ }^{17}$ & & & $13-16$ & $\begin{array}{l}\text { School-based } \\
\text { pupil survey }\end{array}$ \\
\hline Supermarkets ${ }^{a}$ & 80 & - & & \\
\hline Smaller shops ${ }^{\mathrm{a}}$ & 80 & - & & \\
\hline Australia $^{2}$ & & & $12-24$ & $\begin{array}{c}\text { Yearly telephone } \\
\text { survey }\end{array}$ \\
\hline All store types & 80 & 64 & & \\
\hline
\end{tabular}


To our knowledge, no previous study has reported exposure to e-cigarette displays. The adolescents reported substantially less exposure to e-cigarette displays compared to tobacco, which may be due to fewer retail outlets for e-cigarettes. Strong enforcement of the display ban on tobacco products and e-cigarettes is needed to ensure retailers' longterm compliance with the law. Also, continued efforts should minimize minors' exposure to tobacco products through open containers.

As tobacco displays have been found to increase smoking susceptibility and smoking behaviours (i.e. initiation, regular smoking $)^{2-8,11,12,18}$, the observed decrease in exposure may have contributed to fewer smokers. From 2011, daily smoking among Finnish adolescents has decreased. The proportion of daily smokers prior to the display ban was 16\% (2011), and following the ban, it was $12 \%$ (2013), $10 \%$ (2015) and 7\% (2017) ${ }^{19}$. Findings from studies on the effects of display bans on cigarette smoking ${ }^{2-8}$ could in part explain the reduction in smoking prevalence in Finland.

Adolescents still reported noticing tobacco products at the POS in 2017, although the POS display ban had been in effect for several years. Adolescents may observe tobacco packages when the retailer opens the storage unit for customers purchasing tobacco. Another explanation may be the use of specific tobacco storage units with a plain number display, where numbers indicate different cigarette packages sold in the shop. These machines are placed under the supervision and direct vicinity of the cashier, but are operated by customers. It is possible that adolescents have started to perceive these as tobacco displays. This could be avoided by turning the number display to face the cashier instead of the customers, and limiting the operation of the machine to cashiers.

Noticing displayed tobacco somewhat increased in shops and service stations, following the immediate decrease upon implementation of the display ban. This may be a result of less compliance or an increased number of adolescents perceiving tobacco storage units as displays. It is, however, unclear why this would occur in some types of retailers, but not in all retailers. Increased efforts to enforce the ban may be needed in shops and service stations.

\section{Limitations and strengths}

Due to low response rates, the study sample may not be fully representative of the population. However, response rates were similar across years, and therefore, may not have biased the trend in observation of tobacco displays. A potential problem with the measure of noticing tobacco displays is what adolescents perceive as a 'display'. After the display ban was implemented, the tobacco storage units were still frequently visible (although cigarette packages were covered), which may have overestimated participants' perceived observation of tobacco displays. Additionally, self-reported data may have contributed to recall bias. Although exposure to displays may be somewhat misclassified as a consequence, it is unlikely that the misclassification changed over time. We therefore consider the results on trends sufficiently valid. Despite these limitations, this study was strengthened by a lengthy assessment following the display ban, as well as the large number of respondents who were surveyed across Finland.

\section{CONCLUSIONS}

In Finland, the proportion of adolescents noticing tobacco displayed at POS strongly declined after implementing a POS display ban. Findings from this study suggest that the display ban is being adhered to; therefore, we recommend implementation of the display ban with strong enforcement in other countries throughout Europe. The European Union was unsuccessful in implementing a display ban in the 2014 Tobacco Products Directive (TPD) ${ }^{20}$. In order to effectively implement display bans throughout Europe, consideration should be given to revising the EU TPD to include a display ban. Continued strong enforcement is also needed to ensure that the retailers comply with the ban.

\section{REFERENCES}

1. Harper T. Why the tobacco industry fears point of sale display bans. Tob Control. 2006;15:270-271. doi:10.1136/tc.2006.015875

2. Dunlop S, Kite J, Grunseit AC, et al. Out of sight and out of mind? Evaluating the impact of point-of-sale tobacco display bans on smoking-related beliefs and behaviors in a sample of Australian adolescents and young adults. Nicotine Tob Res. 2015;17(7):761-768. doi:10.1093/ntr/ntu180

3. Robertson L, McGee R, Marsh L, Hoek J. A systematic 
review on the impact of point-of-sale tobacco promotion on smoking. Nicotine Tob Res. 2015;17(1):2-17. doi:10.1093/ntr/ntu168

4. Paynter J, Edwards R. The impact of tobacco promotion at the point of sale: A systematic review. Nicotine Tob Res. 2009;11(1):25-35. doi:10.1093/ntr/ntn002

5. Robertson L, Cameron C, McGee R, Marsh L, Hoek J. Point-of-sale tobacco promotion and youth smoking: a meta-analysis. Tob Control. 2016;25(e2):e83-e89. doi:10.1136/tobaccocontrol-2015-052586

6. Henriksen L, Schleicher NC, Feighery EC, Fortmann SP. A longitudinal study of exposure to retail cigarette advertising and smoking initiation. Pediatrics. 2010;126(2):232-238. doi:10.1542/peds.2009-3021

7. Edwards R, Ajmal A, Healey B, Hoek J. Impact of removing point-of-sale tobacco displays: data from a New Zealand youth survey. Tob control. 2017;26(4):392-398. doi:10.1136/tobaccocontrol-2015-052764

8. Van Hurck MM, Nuyts PAW, Monshouwer K, Kunst AE, Kuipers MAG. Impact of removing point-of-sale tobacco displays on smoking behaviour among adolescents in Europe: a quasi-experimental study. Tob Control. 2018. doi:10.1136/tobaccocontrol-2018-054271

9. World Health Organization. WHO Framework Convention on Tobacco Control. Article 1, Use of terms. Geneva: World Health Organization; 2003.

10. World Health Organization. WHO Framework Convention on Tobacco Control: Guidelines for implementation, Article 13. Geneva: World Health Organization; 2013.

11. McNeill A, Lewis S, Quinn C, et al. Evaluation of the removal of point-of-sale tobacco displays in Ireland. Tob Control. 2011;20(2):137-143. doi:10.1136/tc.2010.038141

12. Bogdanovica I, McNeill A, Britton J. Cohort study investigating the effects of first stage of the English tobacco point-of-sale display ban on awareness, susceptibility and smoking uptake among adolescents. BMJ Open. 2017;7(1):e012451. doi:10.1136/bmjopen-2016-012451

13. Tobacco Act, No 549/2016, Finland: https://www.finlex. fi/en/laki/kaannokset/2016/en20160549. Accessed June $1,2018$.

14. Ministry of Social Affairs and Health in Finland. New, stricter Tobacco Act enters into force on 15 August 2016. A press release 102/2016. http://stm.fi/artikkeli/-/ asset_publisher/tupakkalaki-tiukentuu-uusi-lakivoimaan-15-8-2016?_101_INSTANCE_yr7QpNmlJmSj_ languageId=en_US. Accessed June 1, 2018.

15. Best C, Haseen F, van der Sluijs W, et al. Relationship between e-cigarette point of sale recall and e-cigarette use in secondary school children: a cross-sectional study. BMC Public Health. 2016;16(1):310. doi:10.1186/s12889-016-2968-2

16. Pasch KE, Nicksic NE, Opara SC, Jackson C, Harrell MB, Perry CL. Recall of point-of-sale marketing predicts cigar and e-cigarette use among Texas youth. Nicotine Tob Res. 2018;20(8):962-969. doi:10.1093/ntr/ntx237

17. Stead M, Eadie D, MacKintosh AM, Best C, Miller M,
Haseen F, et al. Young people's exposure to point-ofsale tobacco products and promotions. Public Health. 2016;136:48-56. doi:10.1016/j.puhe.2016.03.032

18. Scheffels J, Lavik R. Out of sight, out of mind? Removal of point-of-sale tobacco displays in Norway. Tob Control. 2013;22(e1):e37-e42. doi:10.1136/tobaccocontrol-2011-050341

19. Kinnunen JM, Pere L, Raisamo S, Katainen A, Ollila H, Rimpelä A. The Adolescent Health and Lifestyle Survey 2017: Adolescent smoking, alcohol use and gambling. (In Finnish, with English Abstract). Reports and Memorandums of the Ministry of Social Affairs and Health 2017:28. Helsinki: Ministry of Social Affairs and Health; 2017.

20. Peeters S, Costa H, Stuckler D, McKee M, Gilmore AB. The revision of the 2014 European tobacco products directive: an analysis of the tobacco industry's attempts to 'break the health silo'. Tob Control. 2016;25(1):108117. doi:10.1136/tobaccocontrol-2014-051919

\section{ACKNOWLEDGEMENTS}

We thank Lasse Pere for preparing the data for the analyses. We also thank the adolescents who participated in the surveys by giving their valuable time.

\section{CONFLICTS OF INTEREST}

The authors declare that they have no competing interests, financial or otherwise, related to the current work. JM Kinnunen and AH Rimpelä report grants from Ministry of Social Affairs and Health, during the conduct of the study. The rest of the authors have also completed and submitted an ICMJE form for disclosure of potential conflicts of interest.

\section{FUNDING}

This work was supported by the Ministry of Social Affairs and Health (proposal numbers 201310055, 201410069, STM/322/2017), Finland, and by the Competitive Research Funding of the Tampere University Hospital (proposal numbers 9M090, 9P041, 9P063, 9S055), Tampere, Finland. The funding bodies had no involvement in the design of the study nor in the collection, analysis, interpretation of data, and in writing the manuscript.

\section{PROVENANCE AND PEER REVIEW}

Not commissioned; externally peer reviewed. 